Document downloaded from:

http://hdl.handle.net/10251/81245

This paper must be cited as:

Ferri Azor, JM.; García García, D.; Sánchez Nacher, L.; Fenollar Gimeno, OA.; Balart Gimeno, RA. (2016). The effect of maleinized linseed oil (MLO) on mechanical performance of poly(lactic acid)-thermoplastic starch (PLA-TPS) blends. Carbohydrate Polymers. 147:6068. doi:10.1016/j.carbpol.2016.03.082.

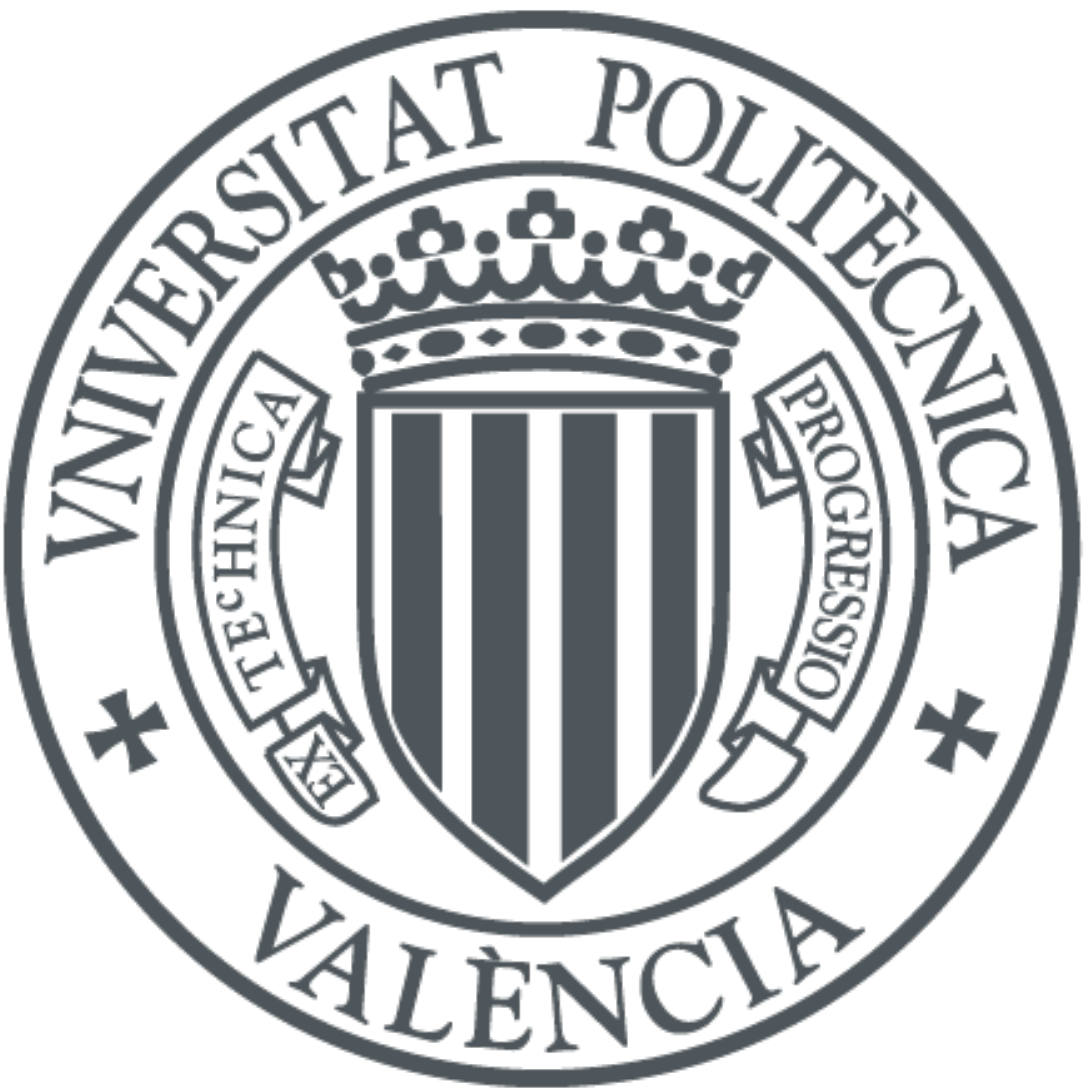

The final publication is available at

http://dx.doi.org/10.1016/j.carbpol.2016.03.082

Copyright Elsevier

Additional Information 


\title{
"The effect of maleinized linseed oil (MLO) on mechanical performance of poly(lactic acid)-thermoplastic starch (PLA-TPS) blends"
}

J.M. Ferri, D. Garcia-Garcia, L. Sánchez-Nacher, O. Fenollar, R. Balart

Instituto de Tecnología de Materiales (ITM)

Universitat Politècnica de València (UPV)

Plaza Ferrandiz y Carbonell 1, 03801, Alcoy, Alicante (Spain)

\begin{abstract}
In this work, poly(lactic acid), PLA and thermoplastic starch, TPS blends (with a fixed content of $30 \mathrm{wt} . \%$ TPS) were prepared by melt extrusion process to increase the low ductile properties of PLA. The TPS used contains an aliphatic/aromatic biodegradable polyester (AAPE) that provides good resistance to aging and moisture. This blend provides slightly improved ductile properties with an increase in elongation at break of $21.5 \%$ but phase separation is observed due to the lack of strong interactions between the two polymers. Small amounts of maleinized linseed oil (MLO) can positively contribute to improve the ductile properties of these blends by a combined plasticizing-compatibilizing effect. The elongation at break increases over $160 \%$ with the only addition of $6 \mathrm{phr}$ MLO. One of the evidences of the plasticizing-compatibilizing effect provided by MLO is the change in the glass transition temperature $\left(\mathrm{T}_{\mathrm{g}}\right)$ with a decrease of about $10{ }^{\circ} \mathrm{C}$. Field emission scanning electron microscopy (FESEM) of PLA-TPS blends with varying amounts of maleinized linseed oil also suggests an increase in compatibility.
\end{abstract}

Keywords: poly(lactic acid); thermoplastic starch; plasticizing; maleinized linseed oil. 


\section{1.- Introduction.}

Due to the high environmental impact, the use of conventional non-biodegradable plastics is being questioned and new environmentally friendly polymers are being demanded and introduced in several industrial sectors. Today, several polymers such as poly(lactic acid)PLA, poly(hydroxybutyrate)-PHB and thermoplastic starch (TPS), among others, find new and attracting uses in different sectors such as automotive (Mulhaupt, 1996) and packaging (Arrieta et al., 2014, Arrieta et al., 2014) industries with increasing use. These polymers are characterized by high environmental efficiency along the whole life cycle as they are obtained from renewable resources (PLA is obtained from corn starch and sugar bagasse, PHB is obtained from bacterial fermentation and TPS combines different plant starches with plasticizers) and can be easily disintegrated in compost conditions (Vroman et al., 2009). In addition to these, some petroleum-based polymers such as poly(caprolactone)-PCL, poly(butylene succinate)-PBS, poly(ester amide)-PEA, etc. offer attracting properties as they can be easily processed and they can biodegrade in different media (Arrieta et al., 2014). Many of the so-called biobased polymers are obtained or derived from different types of starch which plays a key role in their synthesis (Pessione et al., 2014, Poomipuk et al., 2014, Bhatia et al., 2015, Liaud et al., 2015).

Poly(lactic acid), PLA is one of the most promising polymers to replace petroleumbased polymers in the packaging industry (Cheng et al., 2015, Sanyang et al., 2015). This is characterized by balanced mechanical properties, good chemical barrier behavior (Plackett et al., 2006), odorless, biocompatible, bio resorbable (Hutmacher et al., 2001) and, in the last years its cost has been remarkably reduced. The main synthesis route is ring-opening polymerization from lactides obtained from starch (wheat, corn, sugar bagasse, yucca, tapioca roots, among others) depending on its availability (Averous, 2004, Lasprilla et al., 2012). Some of the main drawbacks of PLA are its sensitiveness to moisture, low flexibility, low elongation at break and low toughness. To overcome these intrinsic properties, copolymers represent an interesting alternative. Nevertheless, copolymers are, in general, costly materials. A cost effective solution is the use of natural plasticizers which are interesting from an environmental point of view and 
can be an alternative to traditional petroleum-based plasticizers. Some natural vegetable oils (Yokesahachart et al., 2011) and epoxidized vegetable oils (EVOs) find increasing uses in the plasticization industry (Mohammed et al., 2015, Narute et al., 2015). In addition to these, a wide variety of monomeric (Shi et al., 2011, Tsui et al., 2013) and polymeric plasticizers have been proposed in the last years (Averous, 2004, Ren et al., 2009, Oromiehie et al., 2013). Plasticization mechanisms have been widely studied and the main phenomena are related to the lubricant effect and to the free volume that the plasticizer can provide. Plasticizer molecules placed between two different base polymer chains act as a lubricant with a positive effect on chain mobility. Compatible plasticizers can move into the free volume around the polymer chains. This phenomenon results in several effects: the space between two polymer chains is increased and this reduces the intensity of polymer-polymer interactions. On the other hand, compatibility between the plasticizer and the polymer chains allows entering the plasticizer and this increases intermolecular distance which results in some swelling with a subsequent increase in free volume. As a result of these two phenomena, the plasticizer acts as a lubricant with a remarkable enhancement of polymer chain mobility. A wide variety of plasticizers have been proposed to improve the low intrinsic toughness of neat PLA (Liu et al., 2011). In addition, plasticizers can react with hydroxyl groups located at the end groups of PLA polymer chains with a chain extension effect. This is based on the ability of hydroxyl, carbonyl, carboxyl or other polar groups (Niazi et al., 2015) to chemically react with polymer chains to provide a chain extension or a chemical bridge between two polymers in a blend (compatibilization). Some vegetable oil plasticizers act as internal lubricants that allow chain motion and this leads to improved processing conditions, high thermal stability and ductility.

Blending rigid polymers such as PLA with ductile polymers such as poly(caprolactone), thermoplastic starch, polyethylene, etc. is an attracting alternative to overcome the fragility of brittle polymers in a cost effective way. The main problem related to polymer blends is the miscibility between the components. Thermoplastic starch-TPS, has been proposed as a ductile component in different blends to provide toughness and reduce fragility of brittle polymers (Averous, 2004, Boonprasith et al., 2013). TPS addition can lead to increased flexibility and 
elongation at break (Sahari et al., 2013). Industrial TPSs are based on different starches (wheat, corn, sorghum, yucca, potato, etc.) (Sahari et al., 2013) and plasticizers (glycerol, sorbitol, maltose, glucose, etc. or a combination of these) (Chocyk et al., 2015, Mahieu et al., 2015) that enable easy processing and provide high ductile materials with improved elongation at break, reduced retrogradation effects and improved thermal stability (Zhang et al., 2014, Schmitt et al., 2015). Chemically, starch is constituted of two polysaccharides: amylose and amylopectin. Depending on the their ratio, mechanical properties can vary in a great extent (Raquez et al., 2008, Ren et al., 2009, Oromiehie et al., 2013, Clasen et al., 2015).

One of the main drawbacks of using TPS as co-component in polymer blends is its poor miscibility with polymers such as PLA (Teixeira et al., 2012, Mittal et al., 2015). For this reason, important efforts are being conducted to improve it by using compatibilizer agents. Maleic anhydride (MA) and other esterifying agents have been successfully used to improve compatibility of immiscible or very low miscible polymers (Raquez et al., 2008, Ren et al., 2009, Zhu et al., 2012, Oromiehie et al., 2013, Clasen et al., 2015, Detyothin et al., 2015). Maleinization of TPS with 20 wt.\% glycerol by using reactive extrusion was revealed as a useful technique to increase the compatibility with a biodegradable polyester (Raquez et al., 2008). Same results were obtained with chemical modification of starch with an esterifying agent leading to improved blending with poly(lactic acid) (Shin et al., 2011). PLA-TPS blends containing $15 \mathrm{wt} . \%$ TPS showed improved elongation at break and impact absorbed energy with previous modification with maleic anhydride (Gao et al., 2011). Monomeric plasticizers can also provide compatibilization to immiscible or low miscible polymers. Glycidyl methacrylate was successfully used to modify TPS/PEO (TPEO) for improved formulations with poly(lactic acid) (Shi et al., 2011). High molecular weight polyethylene glycols have demonstrated to provide good compatibilization properties (Yu et al., 2015).

PLA/TPS blends and, in particular, the PLA/TPS blend with 30 wt.\% TPS show balanced properties in terms of improved toughness but the restricted miscibility between the two components leads to a clear phase separation which gives low mechanical performance. As described previously, the highly reactive acid/anhydride groups in maleinized vegetable oils can 
1

2

3

4

5

6

7

8

9

10

11

potentially provide a dual effect on PLA blends: a plasticizing and a compatibilizing/chain extension effect. The aim of this work is the use of thermoplastic starch to provide improved toughness to rigid-brittle poly(lactic acid). Due to the lack of miscibility of TPS and PLA, maleinized linseed oil (MLO) is used as a natural-derived compatibilizer for PLA-TPS immiscible blends. The influence of MLO on thermal, mechanical, morphological properties and its effect on the compatibility of these two restricted miscibility polymers is evaluated.

\section{2.- Experimental.}

\section{1.- Materials.}

Poly(lactic acid), PLA Ingeo ${ }^{\mathrm{TM}}$ Biopolymer commercial grade 6201D was supplied by NatureWorks LLC (Minnetonka, USA). This grade contains 2\% D-lactic acid; it is characterized by a density of $1.24 \mathrm{~g} \mathrm{~cm}^{-3}$ and a melt flow index (MFI) in the $15-30 \mathrm{~g} /(10 \mathrm{~min})$ range measured at $210{ }^{\circ} \mathrm{C}$. Thermoplastic starch commercial grade Mater-Bi® NF 866 was obtained from Novamont SPA (Novara, Italy) and it is produced from maize starch. It shows a melt flow index of $3.5 \mathrm{~g} /(10 \mathrm{~min})$ measured at $150{ }^{\circ} \mathrm{C}$, a density of $1.27 \mathrm{~g} \mathrm{~cm}^{-3}$ and a melt peak located in the $110{ }^{\circ} \mathrm{C}-120{ }^{\circ} \mathrm{C}$ range. This thermoplastic starch is composed of about $15 \%$ of an aliphatic/aromatic biodegradable copolyester (AAPE) (NOVAMONT, 2010). The material used as plasticizer-compatibilizer was a maleinized linseed oil (MLO) VEOMER LIN supplied by Vandeputte (Mouscron, Belgium) with a viscosity of $10 \mathrm{dPa} \mathrm{s}$ at $20^{\circ} \mathrm{C}$ and an acid value of 105 $-130 \mathrm{mgKOH} \mathrm{g}{ }^{-1}$.

\section{2.- Preparation and compatibilization of PLA-TPS blends.}

A constant TPS content of 30 wt.\% was used to evaluate the plasticization compatibilization effect provided by maleinized linseed oil (MLO). This composition has given interesting results in terms of toughness improvement as observed by previous results and reported in the literature (Li et al., 2011). $30 \mathrm{wt} . \%$ TPS also contributes to lower the cost of the material as it is cheaper than PLA while maintaining the overall properties of PLA. PLA-30 wt.\% TPS blends with different maleinized linseed oil (MLO) content as indicated in Table 1 
1

2

were manufactured. The MLO range composition varied in the 0-8 phr (per hundred resin) as previous studies with epoxidized vegetable oils and maleinized oils indicated saturation with relatively low contents close to $10 \mathrm{phr}$. Initially, PLA and TPS were dried at $60{ }^{\circ} \mathrm{C}$ for 24 hours in an air circulating oven. After this, PLA and TPS pellets were mechanically mixed in a zip bag together with the corresponding amounts of MLO. Subsequently, the mixtures were extruded in a twin-screw co-rotating extruder at a rotating speed of $60 \mathrm{rpm}$. The temperature profile was set to $167.5^{\circ} \mathrm{C}, 170{ }^{\circ} \mathrm{C}, 172.5^{\circ} \mathrm{C}$ and $175^{\circ} \mathrm{C}$ from the hopper to the die. After cooling, the extruded materials were pelletized and processed by injection molding in a Meteor 270/75 from Mateu \& Solé (Barcelona, Spain) at an injection temperature of $175^{\circ} \mathrm{C}$. Standard samples for tensile tests and rectangular shapes sizing $80 \times 10 \times 4 \mathrm{~mm}^{3}$ for other characterizations were obtained.

\section{Table 1}

\section{3.- Mechanical characterization.}

Mechanical properties of the blends and individual materials were obtained with standard tensile, flexural, hardness and impact tests. Tensile and flexural properties were obtained in a universal test machine ELIB 30 from S.A.E. Ibertest (Madrid, Spain) at room temperature with the guidelines of the ISO 527-5 and ISO 178 respectively. A $5 \mathrm{kN}$ load cell was used for all tests and the crosshead speed was set to a constant value of $10 \mathrm{~mm} \mathrm{~min}^{-1}$. At least five different samples were tested in both tensile and flexural tests to obtain average values of the main parameters. In addition, a bi-axial extensometer from Ibertest was used to measure the Young Modulus in a more accurate way.

Shore D hardness was measured in a Shore D durometer 673-D from Instrumentos J. Bot S.A. (Barcelona, Spain) as recommended by the ISO 868. With regard to the energy absorption, a Charpy pendulum (1 J) from Metrotec S.A. (San Sebastián, Spain) was used to measure the absorbed energy in impact conditions as recommended by the ISO 179:1993. Five different notched samples were tested and average values were calculated. The geometry of the 
notch was type A with a background radius of $0.25 \pm 0.05 \mathrm{~mm}$; the remaining width of $8.0 \pm 0.2$ $\mathrm{mm}$ and the notch angle is $45^{\circ} \pm 1^{\circ}$.

\section{4.- Microstructural characterization.}

A high-resolution field emission microscope ZEISS ULTRA55 from Oxford Instruments (Oxfordshire, United Kingdom) operated at $2 \mathrm{kV}$ was used to observe the microstructure of cryofractured surfaces. Samples were coated with an ultrathin platinum layer in vacuum conditions in a high vacuum sputter EM MED020 from Leica Microsystems.

\section{5.- Thermal characterization.}

Thermal transitions were studied by differential scanning calorimetry (DSC) in a DSC 821 calorimeter from Mettler-Toledo Inc. (Schwerzenbach, Switzerland) with a heating program from $30{ }^{\circ} \mathrm{C}$ to $350{ }^{\circ} \mathrm{C}$ in nitrogen atmosphere $\left(66 \mathrm{~mL} \mathrm{~min}^{-1}\right)$ at a heating rate of $10{ }^{\circ} \mathrm{C} \mathrm{min}{ }^{-1}$. Degradation at high temperatures was studied by thermogravimetric analysis (TGA) in a TGA/SDTA 851 thermobalance from Mettler-Toledo Inc. (Schwerzenbach, Switzerland). The selected temperature ramp was from $30^{\circ} \mathrm{C}$ to $500{ }^{\circ} \mathrm{C}$ in nitrogen atmosphere $\left(66 \mathrm{~mL} \mathrm{~min}^{-1}\right)$ at a heating rate of $20^{\circ} \mathrm{C} \mathrm{min}^{-1}$.

Dynamic mechanical thermal analysis (DMTA) in torsion mode was done on rectangular samples sizing 40x10x4 $\mathrm{mm}^{3}$ in an oscillatory rheometer AR G2 from TA Instruments (New Castle, USA) equipped with a special clamp system for solid samples. The temperature program was from $-80^{\circ} \mathrm{C}$ to $130{ }^{\circ} \mathrm{C}$ at a heating rate of $2{ }^{\circ} \mathrm{C} \mathrm{min}{ }^{-1}$ at a frequency of $1 \mathrm{~Hz}$ and a maximum deformation $(\gamma)$ of $0.1 \%$.

\section{3.- Results and discussion.}

\section{1.- Effect of MLO on mechanical properties of PLA-TPS blends.}

Unblended PLA possesses a tensile strength of $64 \mathrm{MPa}$ and a tensile modulus of 3590 MPa. These values are higher than most commodity plastics. Nevertheless, PLA is a quite brittle polymer with an elongation at break of about $7 \%$. Addition of a high ductile and flexible 
polymer such as thermoplastic starch provides improved ductile properties but the lack of miscibility of them can lead to lower performance than expected. For this reason, maleinized linseed oil was added at different concentrations to provide plasticization and/or compatibilization effects. Fig. 1a shows the plot evolution of tensile properties of PLA-30TPS with varying maleinized linseed oil (MLO). PLA-30TPS blend offers a tensile strength of 41.5 MPa and a tensile modulus of $2475 \mathrm{MPa}$. With the only addition of $2 \mathrm{phr}$ MLO the tensile strength suffers a decrease up to values of $35.7 \mathrm{MPa}$ which represents a percentage decrease of 14\%. Higher MLO content such as 8 phr MLO leads to tensile strength values of about 28.2 MPa (percentage decrease of almost 32\%). With regard to the tensile modulus, it changes from 2475 for PLA-30TPS blend without MLO to values in the $2200 \mathrm{MPa}-2300 \mathrm{MPa}$ range for MLO content in the $2-8 \mathrm{phr}$ range. It is evident that mechanical resistant properties decrease with increasing MLO content. On the other hand, mechanical ductile properties are remarkably improved with MLO. PLA-30TPS is characterized by an elongation at break of $21.5 \%$ and we observe an increasing tendency up to $6 \mathrm{phr}$ MLO with noticeable higher elongation at break values of $160 \%$. For an MLO content of $8 \mathrm{phr}$, the elongation at break is still higher than raw PLA-30TPS blend but this value is lower than that obtained for $6 \mathrm{phr}$ MLO. This could indicate that an optimum is achieved for phr contents close to $6 \mathrm{phr}$ and higher MLO contents do not provide increased ductile properties. Miscibility of TPS in PLA is poor as referred by some authors (Teixeira et al., 2012, Mittal et al., 2015) and phase separation is the resulting microstructure. Nevertheless, finely rich TPS dispersed phase provides improved toughness and other ductile properties to PLA due to its high flexibility which enables some energy absorption and elongation but in general terms TPS does not act as a plasticizer when blended with PLA. As one can observe, MLO addition leads to a remarkable in elongation at break whilst no remarkable decrease is detected for both tensile strength and tensile modulus. This indicates that MLO provides a clear plasticization effect and the evidence is the noticeable increase in elongation at break. On the other hand, the tensile strength and modulus do not decrease in a great extent thus giving some evidences that in addition to plasticization, other phenomena could occur. It is expectable that maleic anhydride groups in MLO can react with some 
1 hydroxyl groups in PLA end chains (and partially hydrolysed PLA chains during processing) to

2 give a chain extension effect and, on the other hand, MLO can also react with hydroxyl groups

3 in TPS thus leading to a compatibilization effect as observed by the evolution of the mechanical

4 properties.

5

6

Figure 1

7

Fig. $1 \mathrm{~b}$ shows the evolution of the flexural properties as a function of the maleinized

linseed oil (MLO) content. The flexural strength and flexural modulus of unblended PLA is

$116 \mathrm{MPa}$ and $3273 \mathrm{MPa}$ respectively. We observe a decrease in both flexural strength and

flexural modulus with minimum values in the $4-6 \mathrm{phr}$ MLO range up to 45-50 MPa and 2100

MPa for flexural strength and modulus respectively. Over 6 phr MLO a decrease in both mechanical resistant and ductile properties is observed and this could be related to a negative effect due to phase separation (Mikus et al., 2014).

One of the main features of PLA-30TPS blends with MLO is the large increase in the impact-absorbed energy as it can be observed in Table 2. Unblended PLA is characterized by a relatively low energy absorption ability with a Charpy's impact energy of $1.6 \pm 0.3 \mathrm{~kJ} \mathrm{~m}^{-2}$. Physical blend of PLA with TPS leads to a remarkable increase in the energy absorption up to values of $5.3 \mathrm{~kJ} \mathrm{~m}^{-2}$, which represents a percentage increase of about $230 \%$. Despite this remarkable increase, addition of MLO still improves more the energy absorption up to values of about $9.5 \mathrm{~kJ} \mathrm{~m}^{-2}$ for MLO compositions comprised between 4 and $6 \mathrm{phr}$ MLO, which represents a percentage increase of almost 500\% with regard to unblended PLA. For an MLO content of 8 phr we observe the same phenomenon described before with a decrease in the energy absorption due to a negative effect as a consequence of MLO saturation and subsequent phase separation. 
With regard to the Shore D hardness, we observe similar decreasing tendency as other

2 mechanical resistant properties. The Shore D of unblended PLA is 76 and it is decreased up to

368 by blending with TPS but addition of MLO leads to softer materials due to the plasticization

4 effect clearly observable up to 6 phr MLO.

5

6

7

Evolution of Vicat softening temperature (VST) and heat deflection temperature (HDT) follows typical tendency of a mechanical resistant property such as strength and modulus. The VST and HDT values for unblended PLA are $52.8^{\circ} \mathrm{C}$ and $47.6^{\circ} \mathrm{C}$ respectively. A blend of PLA with $30 \mathrm{wt} . \%$ TPS provides improved deformation properties thus leading to lower VST and HDT values of $50.6{ }^{\circ} \mathrm{C}$ and $49.4{ }^{\circ} \mathrm{C}$ respectively. Once again, addition of MLO leads to decreased VST and HDT values up to asymptotic values of $47^{\circ} \mathrm{C}$ and $44{ }^{\circ} \mathrm{C}$ respectively.

\section{2.- Effect of MLO on thermal properties of PLA-TPS blends.}

Table 3 shows a summary of the main thermal parameters obtained by differential scanning calorimetry (DSC) on PLA-30TPS blends with different amounts of maleinized linseed oil (MLO).

\section{Table 3}

As it can be observed, the melt temperature does not vary in a significant way with regard to the reference PLA-30TPS blend. The glass transition temperature slightly decreases with MLO content due to increased polymer chain mobility. There are two possible effects that MLO can provide: a lubricant effect and a decrease in the intensity between polymer chains. Lubricity and gel theories have been extensively used to explain the effects of plasticizers on polymeric structures. Lubricity theory proposes that the plasticizer can exert a lubricant effect which leads to increased chain mobility as the distance between polymer chains increases thus leading to decreased polymer-polymer interactions. On the other hand, the gel theory suggests that the plasticizer contributes to lower polymer-polymer interactions (hydrogen bonds, van der Waals or ionic forces, etc.) which has a positive effect on the overall chain mobility. These 
1 phenomena could explain the observed decrease in Tg values as MLO is added. In addition,

2 MLO can readily react with hydroxyl groups in both PLA end chains and thermoplastic starch

3 chains leading to a combined effect of compatibilization and chain extension with a subsequent

4 decrease in crystallinity which can also contribute to lower polymer-polymer interactions

5 (Chieng et al., 2014). It is important to remark that the only addition of $30 \mathrm{wt} \%$ TPS to PLA

6 leads to a decrease in the glass transition temperature from $65.4{ }^{\circ} \mathrm{C}$ (unblended PLA) to $62.8^{\circ} \mathrm{C}$

7 for the blend. Although these polymers are not fully miscible and phase separation is evident,

8 PLA is able to dissolve a very low amount of TPS chains resulting in a PLA rich phase but the

9 effect of the dissolved TPS chains promotes a decrease in the glass transition temperature. In addition, the cold crystallization temperature follows similar tendency to that observed for $\mathrm{T}_{\mathrm{g}}$. Unplasticized PLA shows a cold crystallization peak at $102{ }^{\circ} \mathrm{C}$ and the blend with $30 \mathrm{wt} . \%$ TPS leads to a decrease in the cold crystallization peak to values of $98.5^{\circ} \mathrm{C}$. Addition of MLO to this blend provides a slight decrease in the cold crystallization temperature up to values of $95.2{ }^{\circ} \mathrm{C}$ for an MLO content of $8 \mathrm{phr}$. This is directly related to increased chain mobility due to the internal lubrication effect that MLO produces (Chieng et al., 2014).

With regard to the thermal stability of PLA-30TPS, Fig. 2 shows a comparative plot of the TGA thermograms for neat PLA and its blends with 30 wt.\% TPS (with and without MLO compatibilizer). We can clearly observe a positive effect of MLO on overall thermal stability with improved thermal degradation temperature as MLO content increases.

\section{Figure 2}

As we can observe, the PLA blend with 30 wt.\% TPS offers improved thermal stability with regard to unblended PLA and this thermal stability is still improved with the addition of maleinized linseed oil (MLO) as observed in Fig. 2. Specifically, the degradation temperature corresponding to $90 \%$ weight loss (T90) is $380{ }^{\circ} \mathrm{C}$, whereas for PLA/30TPS is $408{ }^{\circ} \mathrm{C}$. A significant increase in PLA stability is observed when adding TPS, but still it is higher when the 
blends contains MLO. In fact, a high increase in T90 is observed with values of $415{ }^{\circ} \mathrm{C}, 411.5$ ${ }^{\circ} \mathrm{C}, 416.6^{\circ} \mathrm{C}$ and $420.5^{\circ} \mathrm{C}$ for blends containing $2,4,6$ and 8 phr MLO, respectively.

\section{3.- Effect of MLO on dynamic mechanical thermal properties of PLA-TPS blends.}

Fig. 3a $\& 3 b$ represent the evolution of the storage modulus (G’) and the damping factor $(\tan \delta)$ in terms of temperature for different maleinized linseed oil compositions. The storage modulus (G') at temperatures below $\mathrm{T}_{\mathrm{g}}$ (Fig. 3a) decreases as the MLO content increases. By observing the curve corresponding to the evolution of G' for the PLA-30TPS blend with 6 phr MLO we see the best ductile properties with minimum G' values. Over 6 phr MLO a negative effect occurs thus leading to decreased flexibility as it can be seen by G' values higher than those obtained with an MLO content of $6 \mathrm{phr}$. This could be related to plasticizer saturation leading to phase separation (Mikus et al., 2014). In addition, a clear decrease in the cold crystallization process as previously detected by differential scanning calorimetry (DSC) can be observed. The only presence of TPS is responsible for a slight decrease in the cold crystallization temperature with onset values located at lower temperatures. Although PLA and TPS are not completely miscible a PLA rich phase with some TPS polymeric chains can be expected due to the partial (very low) interactions as evidenced by phase separation. This PLA rich phase is characterized by slightly higher mobility which is responsible for some decrease in both cold crystallization onset and glass transition temperature. Addition of MLO provides two phenomena that result in increased chain mobility. On the one hand, MLO acts as typical plasticizer with a lubricant effect and, on the other hand, MLO contributes to increase PLA-TPS interactions. These two phenomena have a positive effect on overall polymer chain mobility and this results in decreased cold crystallization onset temperature and glass transition temperature as observed in Fig. 3. 
2 blends with different MLO content. The peak is directly related to the glass transition

3 temperature ( $\left.\mathrm{T}_{\mathrm{g} \text { PLA }}\right)$ and as it can be seen, this peak is moved to lower values thus indicating a

4 decrease in the glass transition temperature of the PLA rich phase. Once again, the initial

5 decrease that TPS provides is accentuated by the synergistic effect of MLO addition.

\section{$6 \quad$ 3.4.- Effect of MLO on morphology of PLA-TPS blends.}

7

Fig. 4 shows FESEM images of fractured samples corresponding to unblended PLA, unblended TPS and the PLA blend with 30 wt.\% TPS (PLA-30TPS) (Fig. 4e \& 4f). These pictures show the typical brittle fracture of PLA (Fig. 4a \& 4b) with smooth fracture surface due to inexistent or very low plastic deformation and a ductile fracture corresponding to a flexible polymer, TPS (Fig. 4c \& 4d) with flake formation. These flakes correspond to crystalline plane growth or "crystalline lamellae" located at the amylopectin branches that are fold up because of fracture. These flake structures form parallel-plane blocks and clusters of these blocks form granules separated by porous of amorphous areas in which amylose and plasticizers can be allocated (Hee-Young Kim, 2014). The blend with 30 wt.\% TPS shows a clear phase separation with a PLA rich phase as the matrix and the TPS rich phase as the dispersed component as detected in Fig. 4e \& 4f. This phase separation is related to the lack of affinity between TPS and PLA and this leads for the need of somewhat compatibilization (Huneault et al., 2007). PLA is a hydrophobic polymer whilst TPS is a highly hydrophilic polymer (in fact one of the main drawbacks of TPS is its extremely high moisture sensitiveness). This different polarity is responsible of the lack (or very low) affinity between these two polymers and this leads to a phase separation. For this reason, a compatibilization strategy must be applied to PLA-TPS blends to give materials with interesting properties. This effect is provided by MLO as previously described. 
2 of $2 \mathrm{phr}$ (Fig. 5a \& 5b) leads to improved adhesion/interaction between the two main

3 components in the blend. As the MLO content increases, the compatibility or miscibility

4 between PLA and TPS is improved and it is difficult to observe the dispersed TPS rich phase.

5 As we have previously described, MLO provides a combined effect on these blends. On the one

6 hand, a clear plasticization effect can be observed by mechanical characterization as MLO

7 increases the free volume. This phenomenon has a positive effect on polymer chain mobility as

8 polymer-polymer interactions are lowered and additionally, the plasticizer provides a lubricant

9 effect. On the other hand, a compatibilization effect is achieved by MLO which can interact

with both poly(lactic acid) chain ends and hydroxyl groups in thermoplastic starch thus leading to an overlapped compatibilization and chain extension effect which in turn, is responsible for the observed increase in ductile-flexible properties of PLA-30TPS blends. As the MLO increases the blend becomes saturated and phase separation occurs for MLO content over 6 phr. Fig. 5h shows some voids that can be related to excess MLO.

\section{Figure 5}

\section{4.- Conclusions.}

Thermoplastic starch offers very restricted miscibility with PLA as evidenced by FESEM. Addition of TPS leads to an improvement on toughness due to a microstructure composed of a brittle PLA rich phase in which fine TPS rich microspheres are finely dispersed. This particular microstructure results in improved toughness. The lack of strong PLA-TPS interactions does not allow higher ductile properties. To achieve this, a plasticization strategy with maleinized linseed oil (MLO) has been proposed in this research work. Addition of an environmentally friendly plasticizer derived from vegetable oils, maleinized linseed oil (MLO) at relatively low contents in the $2-6$ phr leads to a remarkable increase in mechanical ductile properties such as elongation at break and impact-absorbed energy due to a combination of different phenomena. Maleinized linseed oil exerts a typical plasticization effect by increasing 
1 the free volume and lowering polymer-polymer interactions and this results in increased chain

2 mobility due to the lubricant effect provided by the plasticizer. On the other hand, the particular

3 chemical structure of maleinized linseed oil, with maleic anhydride groups allows some

4 reactions with hydroxyl groups in both PLA end chains and starch chains resulting in a chain

5 extension and compatibilization effect respectively. With regard to the elongation at break,

6 unblended and unplasticized PLA shows an elongation at break of about $7 \%$. This value is

7 increased by blending PLA with 30 wt. $\%$ TPS up to values of $21 \%$ but the addition of 4-6 phr

8 MLO leads to an elongation at break of $140-160 \%$ respectively. Similar tendency is detected for

9 energy absorption and other ductile properties. Nevertheless, it is important to note that plasticizer saturation occurs for relatively low MLO content. Over 6 phr MLO a decrease in ductility and ductile properties and an increase in mechanical resistant properties can be detected. This saturation can lead to phase separation which in turn is responsible for stress concentration phenomena thus leading to fracture. The plasticization effect of MLO is clearly evident by a decrease in the glass transition temperature $\left(\mathrm{T}_{\mathrm{g}}\right)$ of the PLA rich phase as evidenced by differential scanning calorimetry (DSC) and dynamic mechanical thermal analysis (DMTA). On the other hand, MLO also provides a compatibilization effect that allows improving compatibility between PLA and TPS and this also has a positive effect on overall properties. In general terms, maleinized linseed oil (MLO) is an attractive additive to provide plasticization properties to brittle polymers and also improve compatibility in immiscible or partially miscible polymer blends. In addition is natural origin represents an environmental efficient solution to improve industrial formulations based on biopolymers and biopolymer blends.

\section{Acknowledgements}

This research was supported by the Ministry of Economy and Competitiveness MINECO, Ref: MAT2014-59242-C2-1-R. Authors also thank to "Conselleria d'Educació,

Cultura i Esport" - Generalitat Valenciana, Ref: GV/2014/008 for financial support. 
References.

Arrieta, M. P., Lopez, J., Hernandez, A. \& Rayon, E. (2014). Ternary PLA-PHB-Limonene blends intended for biodegradable food packaging applications. European Polymer Journal, 50, 255-270.

Arrieta, M. P., Lopez, J., Rayon, E. \& Jimenez, A. (2014). Disintegrability under composting conditions of plasticized PLA-PHB blends. Polymer Degradation and Stability, 108, 307-318.

Arrieta, M. P., Samper, M. D., Lopez, J. \& Jimenez, A. (2014). Combined Effect of Poly(hydroxybutyrate) and Plasticizers on Polylactic acid Properties for Film Intended for Food Packaging. Journal of Polymers and the Environment, 22(4), 460-470.

Averous, L. (2004). Biodegradable multiphase systems based on plasticized starch: A review. Journal of Macromolecular Science-Polymer Reviews, C44(3), 231-274.

Bhatia, S. K., Shim, Y.-H., Jeon, J.-M., Brigham, C. J., Kim, Y.-H., Kim, H.-J., et al. (2015). Starch based polyhydroxybutyrate production in engineered Escherichia coli. Bioprocess and Biosystems Engineering, 38(8), 1479-1484.

Boonprasith, P., Wootthikanokkhan, J. \& Nimitsiriwat, N. (2013). Mechanical, thermal, and barrier properties of nanocomposites based on poly(butylene succinate)/thermoplastic starch blends containing different types of clay. Journal of Applied Polymer Science, 130(2), 1114-1123.

Clasen, S. H., Mueller, C. M. O. \& Pires, A. T. N. (2015). Maleic Anhydride as a Compatibilizer and Plasticizer in TPS/PLA Blends. Journal of the Brazilian Chemical Society, 26(8), 1583-1590.

Cheng, H.-Y., Yang, Y.-J., Li, S.-C., Hong, J.-Y. \& Jang, G.-W. (2015). Modification and extrusion coating of polylactic acid films. Journal of Applied Polymer Science, 132(35), 42472.

Chieng, B. W., Ibrahim, N. A., Then, Y. Y. \& Loo, Y. Y. (2014). Epoxidized Vegetable Oils Plasticized Poly(lactic acid) Biocomposites: Mechanical, Thermal and Morphology Properties. Molecules, 19(10), 16024-16038. 
1 Chocyk, D., Gladyszewska, B., Ciupak, A., Oniszczuk, T., Moscicki, L. \& Rejak, A. (2015). Influence of water addition on mechanical properties of thermoplastic starch foils. International Agrophysics, 29(3), 267-273.

Detyothin, S., Selke, S. E. M., Narayan, R., Rubino, M. \& Auras, R. A. (2015). Effects of molecular weight and grafted maleic anhydride of functionalized polylactic acid used in reactive compatibilized binary and ternary blends of polylactic acid and thermoplastic cassava starch. Journal of Applied Polymer Science, 132(28), 42230.

Gao, H., Hu, S., Su, F., Zhang, J. \& Tang, G. (2011). Mechanical, Thermal, and Biodegradability Properties of PLA/Modified Starch Blends. Polymer Composites, 32(12), 2093-2100.

Hee-Young Kim, S. S. P., Seung-Taik Lim (2014). Preparation, characterization and utilization of starch nanoparticles. Colloids and Surfaces B: Biointerfaces, 126, 607-620.

Huneault, M. A. \& Li, H. (2007). Morphology and properties of compatibilized polylactide/thermoplastic starch blends. Polymer, 48(1), 270-280.

Hutmacher, D. W., Goh, J. C. H. \& Teoh, S. H. (2001). An introduction to biodegradable materials for tissue engineering applications. Annals Academy of Medicine Singapore, 30(2), 183-191.

Lasprilla, A. J. R., Martinez, G. A. R., Lunelli, B. H., Jardini, A. L. \& Maciel Filho, R. (2012). Poly-lactic acid synthesis for application in biomedical devices - A review. Biotechnology Advances, 30(1), 321-328.

Li, H. \& Huneault, M. A. (2011). Effect of Chain Extension on the Properties of PLA/TPS Blends. Journal of Applied Polymer Science, 122(1), 134-141.

Liaud, N., Rosso, M.-N., Fabre, N., Crapart, S., Herpoel-Gimbert, I., Sigoillot, J.-C., et al. (2015). L-lactic acid production by Aspergillus brasiliensis overexpressing the heterologous ldha gene from Rhizopus oryzae. Microbial Cell Factories, 14, 66.

Liu, H. \& Zhang, J. (2011). Research Progress in Toughening Modification of Poly(lactic acid). Journal of Polymer Science Part B-Polymer Physics, 49(15), 1051-1083. 
Mahieu, A., Terrie, C. \& Youssef, B. (2015). Thermoplastic starch films and thermoplastic starch/polycaprolactone blends with oxygen-scavenging properties: Influence of water content. Industrial Crops and Products, 72, 192-199.

Mikus, P. Y., Alix, S., Soulestin, J., Lacrampe, M. F., Krawczak, P., Coqueret, X., et al. (2014). Deformation mechanisms of plasticized starch materials. Carbohydrate Polymers, 114, 450-457.

Mittal, V., Akhtar, T. \& Matsko, N. (2015). Mechanical, Thermal, Rheological and Morphological Properties of Binary and Ternary Blends of PLA, TPS and PCL. Macromolecular Materials and Engineering, 300(4), 423-435.

Mohammed, F. S., Conley, M., Saunders, S. R., Switzer, J., Jha, R., Cogen, J. M., et al. (2015). Epoxidized linolenic acid salts as multifunctional additives for the thermal stability of plasticized PVC. Journal of Applied Polymer Science, 132(13), 41736.

Mulhaupt, R. (1996). The use of renewable resources: Possibilities and limitations. Chimia, 50(5), 191-198.

Narute, P., Rao, G. R., Misra, S. \& Palanisamy, A. (2015). Modification of cottonseed oil for amine cured epoxy resin: Studies on thermo-mechanical, physico-chemical, morphological and antimicrobial properties. Progress in Organic Coatings, 88, 316324.

Niazi, M. B. K., Zijlstra, M. \& Broekhuis, A. A. (2015). Influence of plasticizer with different functional groups on thermoplastic starch. Journal of Applied Polymer Science, 132(22), 42012.

NOVAMONT (2010). "Copoliéster alifático/aromático biodegradable (AAPE)." from http://patentados.com/invento/poliesteres-alifaticos-aromaticos-biodegradables.html.

Oromiehie, A. R., Lari, T. T. \& Rabiee, A. (2013). Physical and thermal mechanical properties of corn starch/LDPE composites. Journal of Applied Polymer Science, 127(2), 11281134.

Pessione, A., Zapponi, M., Mandili, G., Fattori, P., Mangiapane, E., Mazzoli, R., et al. (2014). Enantioselective lactic acid production by an Enterococcus faecium strain showing 
potential in agro-industrial waste bioconversion: Physiological and proteomic studies. Journal of Biotechnology, 173, 31-40.

Plackett, D. V., Holm, V. K., Johansen, P., Ndoni, S., Nielsen, P. V., Sipilainen-Malm, T., et al. (2006). Characterization of L-potylactide and L-polylactide-polycaprolactone copolymer films for use in cheese-packaging applications. Packaging Technology and Science, 19(1), 1-24.

Poomipuk, N., Reungsang, A. \& Plangklang, P. (2014). Poly-beta-hydroxyalkanoates production from cassava starch hydrolysate by Cupriavidus sp KKU38. International Journal of Biological Macromolecules, 65, 51-64.

Raquez, J.-M., Nabar, Y., Srinivasan, M., Shin, B.-Y., Narayan, R. \& Dubois, P. (2008). Maleated thermoplastic starch by reactive extrusion. Carbohydrate Polymers, 74(2), $159-169$.

Ren, J., Fu, H., Ren, T. \& Yuan, W. (2009). Preparation, characterization and properties of binary and ternary blends with thermoplastic starch, poly(lactic acid) and poly(butylene adipate-co-terephthalate). Carbohydrate Polymers, 77(3), 576-582.

Sahari, J., Sapuan, S. M., Zainudin, E. S. \& Maleque, M. A. (2013). Thermo-mechanical behaviors of thermoplastic starch derived from sugar palm tree (Arenga pinnata). Carbohydrate Polymers, 92(2), 1711-1716.

Sanyang, M. L. \& Sapuan, S. M. (2015). Development of expert system for biobased polymer material selection: food packaging application. Journal of food science and technology, 52(10), 6445-6454.

Schmitt, H., Guidez, A., Prashantha, K., Soulestin, J., Lacrampe, M. F. \& Krawczak, P. (2015). Studies on the effect of storage time and plasticizers on the structural variations in thermoplastic starch. Carbohydrate Polymers, 115, 364-372.

Shi, Q., Chen, C., Gao, L., Jiao, L., Xu, H. \& Guo, W. (2011). Physical and degradation properties of binary or ternary blends composed of poly (lactic acid), thermoplastic starch and GMA grafted POE. Polymer Degradation and Stability, 96(1), 175-182. 
Shin, B. Y., Jang, S. H. \& Kim, B. S. (2011). Thermal, Morphological, and Mechanical Properties of Biobased and Biodegradable Blends of Poly(lactic acid) and Chemically Modified Thermoplastic Starch. Polymer Engineering and Science, 51(5), 826-834.

Teixeira, E. d. M., Curvelo, A. A. S., Correa, A. C., Marconcini, J. M., Glenn, G. M. \& Mattoso, L. H. C. (2012). Properties of thermoplastic starch from cassava bagasse and cassava starch and their blends with poly (lactic acid). Industrial Crops and Products, 37(1), 61-68.

Tsui, A., Wright, Z. C. \& Frank, C. W. (2013). Biodegradable Polyesters from Renewable Resources. Annual Review of Chemical and Biomolecular Engineering, Vol 4. J. M. Prausnitz. 4: 143-+.

Vroman, I. \& Tighzert, L. (2009). Biodegradable Polymers. Materials, 2(2), 307-344.

Yokesahachart, C. \& Yoksan, R. (2011). Effect of amphiphilic molecules on characteristics and tensile properties of thermoplastic starch and its blends with poly(lactic acid). Carbohydrate Polymers, 83(1), 22-31.

Yu, Y., Cheng, Y., Ren, J., Cao, E., Fu, X. \& Guo, W. (2015). Plasticizing effect of poly(ethylene glycol)s with different molecular weights in poly(lactic acid)/starch blends. Journal of Applied Polymer Science, 132(16), 41808.

Zhang, Y., Rempel, C. \& Liu, Q. (2014). Thermoplastic Starch Processing and CharacteristicsA Review. Critical Reviews in Food Science and Nutrition, 54(10), 1353-1370.

Zhu, R., Liu, H. \& Zhang, J. (2012). Compatibilizing Effects of Maleated Poly(lactic acid) (PLA) on Properties of PLA/Soy Protein Composites. Industrial \& Engineering Chemistry Research, 51(22), 7786-7792. 


\section{Table captions}

2 Table 1.- Summary of the compositions and labelling of the PLA-TPS blends with varying 3 amounts of maleinized linseed oil (MLO).

4 Table 2.- Variation of Charpy's impact energy, Shore D hardness, VST and HDT of PLA$5 \quad$ 30TPS blends with different amounts of maleinized linseed oil (MLO).

6 Table 3.- Main thermal parameters of the PLA-30TPS blend with different MLO contents 7 obtained by differential scanning calorimetry (DSC): glass transition temperature $\left(\mathrm{T}_{\mathrm{g}}\right)$, cold 8 crystallization temperature $\left(\mathrm{T}_{\mathrm{cc}}\right)$ and enthalpy $\left(\Delta \mathrm{H}_{\mathrm{cc}}\right)$ and melt temperature $\left(\mathrm{T}_{\mathrm{m}}\right)$ and enthalpy $9\left(\Delta \mathrm{H}_{\mathrm{m}}\right)$. 


\section{Figure legends}

2 Figure 1.- Plot evolution of mechanical tensile (a) and flexural (b) properties of PLA-30TPS

3 blend with varying maleinized linseed oil (MLO) content.

4 Figure 2.- Comparative thermogravimetric curves for unblended PLA, PLA-30TPS and PLA$5 \quad$ 30TPS with maleinized linseed oil (MLO).

6 Figure 3.- Comparison of the evolution of the storage modulus $\left(G^{\prime}\right)(a)$ and damping factor (tan $7 \quad \delta$ )(b) for unblended PLA, PLA-30TPS and PLA-30TPS with different maleinized linseed oil 8 (MLO) content.

9 Figure 4.- FESEM images from cryofractured surfaces of a) PLA at 1000X, b) PLA at 5000X, 10 c) TPS at 1000X, d) TPS at 5000x, e) PLA-30 wt.\% TPS at 1000X and f) PLA-30 wt.\% TPS at $115000 X$.

12 Figure 5.- FESEM images of PLA-30TPS blends with different maleinized linseed oil (MLO) content at different magnifications, a) 2 phr MLO at 1000X, b) 2 phr MLO at 10000X, c) 4 phr 14 MLO at 1000X, d) 4 phr MLO at 10000X, e) 6 phr MLO at 1000X, f) 6 phr MLO at 10000X, g) $158 \mathrm{phr}$ MLO at $1000 \mathrm{X}, \mathrm{h}) 8 \mathrm{phr}$ MLO at $10000 \mathrm{X}$. 